\title{
COPIM•
}

\section{COPIM response to new UKRI Open Access Policy}

Community-led Open Publication Infrastructures for Monographs

Published on: Aug 11, 2021

DOI: 10.21428/785a6451.7bb97ac2

License: Creative Commons Attribution 4.0 International License (CC-BY 4.0). 


\section{COPIM (Community-led Publication Infrastructures for Monographs) welcomes the announcement of UK Research and Innovation (UKRI)'s open access (으)_policy, which will:}

- include monographs, chapters \& edited collections from 1 January 2024;

- require the final version of a publication or accepted manuscript to be made open access via a publisher's website, a platform or a repository, within a maximum of 12 months of publication;

- and recommend Creative Commons Attribution ( $\underline{\mathrm{CC} B Y}$ ) licensing, while other Creative Commons permissions such as Attribution Non-Commercial ( $\underline{\text { BY NC) }}$ and Attribution Non-Derivative (BY ND) licences are also permitted.

At COPIM, we believe that a shift to open access for academic books is not only possible, but necessary. We - together with a larger network of projects committed to community-led and not-for-profit approaches to scholarly publishing - are developing infrastructures and business models to support publishers and authors in making their long-form research output openly available without relying on embargoes or authorfacing charges (otherwise known as Book Processing Charges or BPCs). These infrastructures are already supporting university and scholar-led presses to publish open access books without these constraints.

We are pleased to note that both UKRI's summary of the responses to its consultation on the new policy and its explanation of its policy_changes emphasised that COPIM is well positioned to support a transition towards open access for long-form academic work, and we look forward to doing so. 1

The experience of our consortial partners who publish open access books is that there is a wide and deep appetite among readers for open access to long-form academic research. Furthermore, given the importance of the book to the creation and dissemination of Humanities and Social Science research, it is vital that we achieve immediate and equitable open access routes for books. The alternative is a future in which access to Humanities and Social Sciences research is limited and expensive, and these disciplines increasingly marginalised.

In this response, we would like to briefly outline how COPIM and COPIM's consortial partners are already supporting embargo- and BPC-free open access for books, and in what ways the infrastructures and models built by COPIM will help to support other presses to do so. We would also like to outline how we feel the UKRI open access 
policy could be extended further, and what we would like to see from any future policies for open access books, based on our initial response to the UKRI open access consultation.

COPIM, a £3.6 million project led by an international partnership of universities, libraries, open access publishers and infrastructure providers, is funded by Research England and Arcadia Fund, and we are carrying out work in key areas to provide material and systemic support for open access book publishing. We are doing this by building open, modular and interoperable infrastructure, owned and governed by the academic community, to address the key technological, structural, and organisational hurdles that stand in the way of the wider adoption and impact of open access books.

This includes:

- The Open Book Collective, comprising OA publishers and service providers, university librarians, and academic researchers who work together to create a sustainable non-profit, community-governed hub for open book publishing, the mission of which is to build and maintain infrastructure to support the publication, discovery, dissemination, and preservation of OA books via a range of flexible revenue streams, and to make those books and their infrastructure better integrated with and more legible to library research systems;

- A revenue model called 'Opening the Future' that enables presses to 'flip' from closed-access to open access publishing, by using library subscription to a closedaccess backlist to support the publication of an open access frontlist. Two presses, Central European University_Press and Liverpool University Press, are already implementing this model and it has already funded its first open access books;

- An Open Dissemination System, called 'Thoth', enhancing the discovery of open access books using open metadata, thus already ensuring compliance with metadata standards encouraged by funders such as UKRI. The Open Dissemination System has already been fully implemented by Open Book Publishers, punctum books, and mediastudies.press, and is in the process of being readied for adoption by more presses;

- Technical methods for effectively archiving complex digital research publications, thus supporting publishers to comply with any long-term preservation requirement of future funder policies, with a pilot case archiving a subset of publications at a number of locations including the British Library; 
- A pilot of representative experimental books built on top of existing open source tools and platforms, together with technologies and cultural strategies to promote the discovery and reuse of open access books, and to showcase and support the continually-emerging diversity of long-form academic publishing;

- Best practices for the community governance of open publishing infrastructures, scholar-led presses and consortia guided by community values, which have been developed in the process of devising the governance models for the infrastructures that COPIM is building.

COPIM is already more than halfway to completing our objectives, and the infrastructures, workflows and best practices we are developing will be fully operational well before 1 January 2024, when the UKRI policy for books will take effect. Moreover, COPIM's consortial partners include presses who have already been publishing open access books for many years, often without relying on Book Processing Charges and without embargoes.

Although we welcome UKRI's support for open access books in this policy, we also want to highlight some areas of concern, as well as elements we would like to see included in future open access policies for books. This is particularly significant given that the UKRI consultation on this policy stated that

a detailed REF-specific OA consultation will be launched no later than six months after the UKRI policy is announced $\underline{2}$

and that any policy for the REF would affect a much larger number of publications. $\underline{3}$

At COPIM, we value full and equitable open access to research output, and this is why we have argued strongly against the inclusion of any kind of embargo period in future policies during the 2020 consultation period, noting evidence suggesting that an embargo period has no discernable impact on publisher sales. $\underline{4}$ We would also point to the experience of our consortial partners that shows it is possible to devise business models for open access books that do not require an embargo, as well as our own work in this area, described above.

Furthermore, we have also argued in our response against the inclusion of a 'suitable publisher' exemption. $\frac{5}{}$ We note the range and variety of publishers that publish widely in the Humanities and Social Sciences and that already either have an open access programme or publish fully in open access, $\underline{6}$ which might well suffice to fully cover researchers' needs - but which also indicate that it is entirely possible for 
publishers both large and small to publish open access books. For smaller publishers, we would like to highlight the variety of support offers that we are working hard to put in place so as to enable smaller presses to comply with UKRI's open access mandate - for more details, we refer the reader to the above list of different types of non-profit, community-governed infrastructure that COPIM is building. In that respect, we would particularly like to highlight COPIM's work on Thoth, a fully open metadata creation and dissemination system for OA books, and would be keen to offer our expertise in the ongoing process of developing UKRI's emerging guidance on metadata and PID recommendations, which Thoth would aim to support. $\underline{7}$

We are concerned that such an exemption clause might provide an 'easy' way out of publishing open access for both publishers and authors, where either side can argue either that they are a 'specialised press' offering an unique service; or that their book can only be published by such a 'specialised press'. We are keen to know more about the proposed assessment mechanisms that would decide on questions of who counts as 'the only suitable publisher in the field', what the criteria for this would be, and who would be the final arbitrator of such decisions. We hope that this will be forthcoming in 2022.

At COPIM, we would also like to see trade books included in any open access policy. Whether a book is a monograph or a trade book is dependent on a publisher's decision, and the policy does not (at this stage) ask for any transparency about that decisionmaking process, instead leaving it for the publisher and author to decide what qualifies as a trade book. $\underline{8}$ We argue that the definition of what constitutes a trade book should be either made more transparent or - and this would be our preferred option - any output that receives UKRI funding, whether it is a specialised monograph or a trade book, should be made available in open access, as there is currently no evidence that this would harm sales and might even promote the dissemination of the book. $\underline{9}$

We also note that the explicit exclusion of textbooks is a missed opportunity. Similar to trade books, the underlying categorisations of what constitutes a textbook are fluid and often open to individuals' or institutions' interpretation; guidance by UKRI would have been a timely intervention in the continuing work to make textbooks more equitable. $\underline{10}$

Finally, we are keen to learn more about how the funding ring-fenced for open access books will be made available. Any policies from funding bodies should be backed up with the infrastructural and financial provisions needed for publishers and authors to 
be able to fulfill them equitably. Current BPC levels, set mainly by commercial publishers, are too high and unaffordable for the majority of institutions, while any funding made available without a cap on BPCs and without support for alternative funding routes would risk entrenching the BPC model as the major or only method of funding OA books, as argued by our former COPIM colleague Sam Moore. Instead, we propose that funding bodies invest in open source infrastructure for the production of OA books, and that this infrastructure is governed and run by the communities involved in academic publishing themselves on a not-for-profit basis. COPIM itself is seeking to implement this type of approach. As we note in our response to the consultation, if funding is provided for scholars in the UK to publish in OA only by paying for BPCs, this will create further inequalities in access to publishing for scholars in the so-called Global South (also see $\underline{\text { Aguado-López and Becerril-García, }}$ 2020).

Our ScholarLed consortial partners Mattering Press, meson press, $\underline{\text { Open Humanities }}$

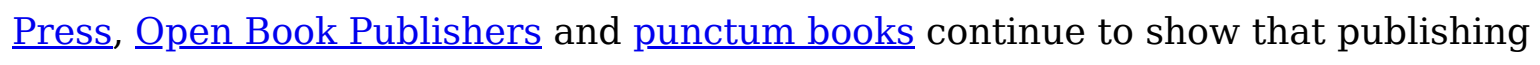
books open access is possible even for small, scholar-led presses, while university presses such as Liverpool University_Press and Central European University_Press are demonstrating leadership within the university press sector by embracing a shift to open access without embargoes or author fees. Publishers such as MIT Press and Cambridge University_Press have also announced new models to fund open access books that do not rely on Book Processing Charges or so-called Transformative Agreements. COPIM's work is further evidence that the transition to open access for academic books is already underway, and practical support is being put in place to enable its expansion in a way that fosters an open, equitable, bibliodiverse and community-governed publishing ecosystem.

The new UKRI policy marks an important step forward along this journey. COPIM eagerly looks forward to further details on possible exemptions as well as on the provision of funding routes for long-form publishing. As highlighted above, COPIM's collaborative, not-for-profit approach provides an alternative to support presses to comply with UKRI's policy without relying on BPCs.

At COPIM, we look forward to a future in which academic books are freely and openly accessible, and we will continue to work to make this a reality.

- If you are a library interested in subscribing to Opening the Future or a press interested in implementing it, or if you would like to know more about this particular model, visit https://openingthefuture.net/ or email OppeningTheFuture@copim.ac.uk. 
- Libraries and presses interested in learning more about COPIM's collaborative multistakeholder collective and platform, please get in touch with COPIM's Work Package

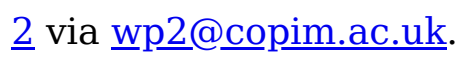

- Presses interested in learning more about Thoth, COPIM's open metadata system, please visit thoth.pub, or contact wpㄷ@ㄷpim.ac.uk.

- And researchers, presses, and libraries interested in experimental approaches to long-form publishing in the Humanities and Social Sciences, please explore our recent report, visit copim.pubpub.org/work-package-6 or get in touch with wpㅡ@opim.ac.uk.

- Finally, if you would like to learn more about the project as a whole, email info@copim.ac.uk, visit www.copim.ac.uk or our Open Documentation site at copim.pubpub.orgL, and follow us on Twitter @COPIMproject.

\section{Consortial Members of COPIM}

COPIM is an international partnership comprising

- universities: Coventry_University, Birkbeck, University_of London, Lancaster University, and Trinity College, Cambridge;

- established scholar-led open access presses, represented through the $\underline{\text { ScholarLed }}$ consortium, which consists of $\underline{\text { Open Book Publishers, }}$ punctum books, $\underline{\text { Open }}$ Humanities Press, Mattering Press, and meson press;

- libraries: University of California Santa Barbara (UCSB) Library, Loughborough University_Library, the British Library;

- infrastructure providers: the Directory of Open Access Books (DOAB), Jisc $\underline{11}$;

- and membership organisations: the Digital Preservation Coalition.

\section{Contact COPIM}

- Email: info@copim.ac.uk

- Twitter: @ $\underline{\text { COPIMproject }}$

- Website: https://www.copim.ac.uk/

- Open documentation site: https://copim.pubpub.org/

Header image by César Viteri on Unsplash

\section{Footnotes}

1. 
i.e. UKRI Open Access Policy: explanation of policy_changes, p.6: "We will work closely with the sector in implementing our policy and to support the wider development of open access books. We note there are already sector-led initiatives, some supported by UKRI such as OAPEN-UK and Community-led Open Publication Infrastructures for Monographs (COPIM)."

ibid., p. 7: "In assessing the open access landscape, many publishers and university presses have (or are developing) open access models. Initiatives such as COPIM will further aid development."

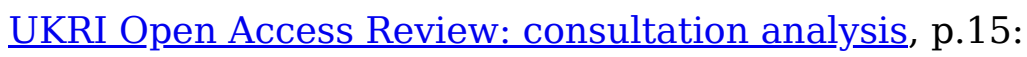

"There was also broad support for UKRI encouraging innovative outlets. Opportunities presented by the outcomes of the Community-led Open Publication Infrastructure for Monographs (COPIM) project was also mentioned. Some respondents also suggested that financial support from UKRI should be multi-year to provide stability and allow for continuity of planning."

ibid., p. 16: "For long-form outputs, 63\% of respondents felt UKRI could do more to support infrastructure (with the highest levels among HEIs at $82 \%$ and publishers at $76 \%)$. Several referred to the need for support for BPCs, but other initiatives cited as meriting support include DOAB and Jisc services, particularly the Publications Router and SHERPA. Other suggestions for support included OAPEN, SCOSS, Unpaywall and COPIM. Several felt that resources would be better spent working with existing providers such as Jisc to enhance the accessibility, usability and readability of digital long-form outputs."

ibid., p. 120-121: "There was also broad support for UKRI encouraging innovative outlets; one publisher suggested a pilot fund should be available during a voluntary phase, where business models could be tested. There should also be funding to invest in innovative approaches such as Open Library of the Humanities (although OLH publishes journals, rather than monographs) and Knowledge Unlatched (KU). Opportunities presented by the outcomes of the COPIM project were also mentioned. Funding to support DOAB and to develop SHERPA services was also welcomed. (p120-121).

ibid., p. 127. "Respondents also suggested that UKRI considered the role that initiatives such as OAPEN and COPIM might play in developing and providing infrastructure for OA monographs." $\doteq$ 
2. See Paragraph 31 of UKRI Open Access Review: Consultation (25 March 2020), https://www.ukri.org/wp-content/uploads/2020/10/UKRI-231020-OpenAccessReviewConsultation25Mar20.pdf $\underline{\text { p }}$

3. The potential costs for an an open access mandate for monographs for the next REF cycle were modelled in 2017, based on REF 2014 volume. See Martin Paul Eve, Kitty Inglis, David Prosser, Lara Speicher, and Graham Stone. 2017. “Cost Estimates of an Open Access Mandate for Monographs in the Uk's Third Research Excellence Framework”. Insights 30 (3): 89-102. DOI: https://doi.org/10.1629/uksg.392 4. See e.g.

Snijder, R. (2010). The profits of free books: an experiment to measure the impact of open access publishing. Learned Publishing, 23(4), 293-301.

https://doi.org/10.1087/20100403

or Snijder, R. (2019) The deliverance of open access books : examining usage and dissemination. https://hdl.handle.net/1887/68465

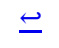

5. see UKRI Open Access Policy,o par 17, p.4:

"UKRI recognises there may be rare instances where meeting open access requirements for long-form publications may not be possible. Therefore, the following exemptions may apply:

a. where the only appropriate publisher, after liaison and consideration, is unable to offer an open access option that complies with UKRI's policy." $ヒ$

6. See e.g.

- the more than 70 publishers listed on the Radical OA Collective's website,

- this list of open access publishers maintained by_open Book Publishers, or

- the Open Access in Media Studies list. $\subseteq$

7. While UKRI asserts that metadata and PID requirements for OA books are currently out of scope - UKRI OA policy, par 18, p.4 “UKRI encourages the adoption of metadata standards and persistent identifiers for long-form research outputs, but they are not currently a requirement of this policy" - a set of future 
recommendations on that front would tremendously help publishers to ensure compliance with the policy, including machine-readable acknowledgement of funding received by UKRI. $\doteq$

8.

It seems noteworthy here that while making a case for the exclusion of trade books in the main body of the policy, the conceptual fluidity existing between classifications of research monographs and trade books is also implied in

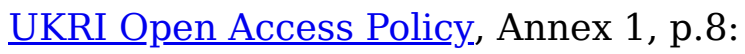

"The decision of whether a book should be considered a trade book or an academic monograph, is at the discretion of the author and publisher."

which seems to leave ample space for further confusion on the side of presses as well as authors. $\subseteq$

9.

see e.g. SPARC Europe's overview of studies pertaining to OA journal articles, and Ronald Snijder's research on the potential citation advantage of OA for monographs.

Snijder, R. Revisiting an open access monograph experiment: measuring citations and tweets 5 years later. Scientometrics 109, 1855-1875 (2016).

https://doi.org/10.1007/s11192-016-2160-6

$\underline{\varphi}$

10. see e.g. Ball (2020) The cost of e-books is hobbling university teaching, and https://blogs.ucl.ac.uk/open-access/2021/03/17/ebooks-webinar/ for a discussion of recent issues with textbook availability in the UK. $匚$

11. See also Robertson (2021) Supporting_open access monographs without the costs of book processing_charges. Jisc Research. $\_$ 